\title{
Feasibility study on the application of carbon dioxide phase change fracturing technology in a foundation pit of an open cut tunnel
}

\author{
Shijie Liu ${ }^{1}$, Zhenghong Huang ${ }^{2}$ \\ China Construction Third Bureau First Engineering Co., LTD., Wuhan, 430040, Hubei, China \\ ${ }^{2}$ Corresponding author

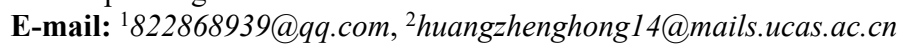

Received 1 November 2019; accepted 10 November 2019

DOI https://doi.org/10.21595/vp.2019.21156

Check for updates

Copyright (C) 2019 Shijie Liu, et al. This is an open access article distributed under the Creative Commons Attribution License, which permits unrestricted use, distribution, and reproduction in any medium, provided the original work is properly cited.

\begin{abstract}
Carbon dioxide phase change fracturing technology is a brand-new and efficient cracking and tunneling technology. Because the method utilizes the change of carbon dioxide state, it belongs to a pure physical process. By adjusting the release rate of gaseous substances, it can effectively control the pressure of the gas, and achieve micro vibration, zero flying stone, zero toxic gas emission, and no micro harmful effect of shock wave, but the application of carbon dioxide phase change cracking technology in urban foundation pit excavation is less. In this paper, through the analysis of three different cracking parameters of urban foundation pit excavation process, it is found that when the diameter of the cracked pipe is $85 \mathrm{~mm}$, the construction safety can be guaranteed. In addition, according to the on-site cracking effect, the carbon dioxide phase change cracking technology is a safe, reliable, relatively economical and efficient excavation technology under urban complex environmental conditions, and will not affect the surrounding environment during use, but Its cracking efficiency has a great relationship with the air surface.
\end{abstract}

Keywords: carbon dioxide, cracking, phase change, vibration.

\section{Introduction}

In urban underground space projects (such as subway tunnels, subway stations and underground space civil air defense projects, etc.), the above regulations on safety, vibration and environmental hazards are very strict. First of all, with the development and utilization of underground urban space projects, the coexistence of operational construction (construction) and post-construction rock excavation projects in the early stage of construction (to be put into production) is widespread. In order to improve the excavation efficiency, the explosive blasting method is generally preferred, and the generated ground, underground and structural vibrations easily exceed the vibration control standards, which affects the normal use of underground structures (structures). Secondly, the surrounding environment of the city is complex (such as urban existing buildings, structures, municipal pipelines, envelope structures, etc.), and many traditional limited blasting schemes will lead to many constraints and safety hazards [1-3].

Carbon dioxide high-pressure gas cracking technology was first invented in the 1950 s by the British company Cardox and the American company Airdox [4], mainly used in coal mining in high gas mines [5, 6]. Until the 1980s, Singh [7] pointed out in the PCF (Penetrating Cone Fracture) concept that the liquid $\mathrm{CO}_{2}$ phase change rock breaking technology has no explosive blasting restrictions, and can be operated with high efficiency and is suitable for rock excavation. The mechanism of $\mathrm{CO}_{2}$ cracking is a physical change, and there is no open flame or spark during use, which improves the safety of the technology in all aspects. It is not restricted by the control of explosives, and the scope of use is limited. It can be applied to coal mines and non-coal mines (coal (rock) roadway excavation, working face falling coal, forced blasting topping, coal bunker clearing, etc.), structure Demolition, open air and downhole are suitable and unsuitable for explosive blasting and can replace explosives. In some countries, $\mathrm{CO}_{2}$ cracking equipment has been widely used in boiler cleaning, building demolition, blasting operations in special areas, and 
has obtained safety certification in the United Kingdom, Germany, New Zealand and other countries. It is an advanced concept, safe method and remarkable effect. Rock breaking technology.

Wei Gang [8] and Zhu Yucheng [9] successfully solved the problem of suspended roof in the working area roadway triangle by carbon dioxide cracking blasting in the canopy of the triangle section of the fully mechanized mining face; through the safety and economy of carbon dioxide cracking blasting and gunpowder blasting Comparing the benefits, it is found that carbon dioxide cracking blasting will not damage the roadway and working face support; the average yield per working surface is increased by $23.25 \%$, which has significant economic effects. Wei Haidong [10] on the mining process of Xinjing Mine fully mechanized mining face the hard roof is subjected to the forced ceiling test of carbon dioxide pre-cracking, which can basically meet the technical requirements of production forced ceiling. In order to study the effect of carbon dioxide cracking on rock mass blasting, Zeng Yongqing [11] carried out the liquid carbon dioxide cracking test of large-scale concrete, and studied the dynamic strain value and pressure value at a certain distance from the cracking center.

However, carbon dioxide phase change cracking technology is less used in urban foundation pit excavation. In this paper, the feasibility of the vibration response, safety and economy of the excavation process of carbon dioxide cracking technology in a city excavation foundation pit is studied.

\section{Application background}

According to the site investigation, the west side of a foundation pit is an open space, the local section has an intercity tunnel, and the east side has Sheraton Hotel, Apartment Hotel and International Convention and Exhibition Center. The basement of the Convention and Exhibition Center is a two-story underground structure with a depth of about $11.5 \mathrm{~m}$. The distance between the structural edges and the working well is 4.6-19 m. During the excavation of the foundation pit, to ensure the normal operation of the exhibition center, the foundation pit is opened. During the excavation process, it is necessary to reduce the influence on the surrounding structures and equipment rooms, control rooms and pipelines, and control the vibration and noise generated by the blasting.

Therefore, it is extremely urgent to choose a rock breaking technology method that is safe and reliable, with high construction efficiency and small environmental impact during the excavation process. According to the on-site construction environment, construction schedule requirements and the impact of the construction process on the surrounding environment, the stone-breaking solutions that can be selected jointly are: (1) Controlled blasting; (2) Hydraulic splitting; (3) Carbon dioxide phase change fracturing technology.

\subsection{Controlled blasting}

Controlled blasting is based on engineering requirements and specific conditions such as blasting environment, scale, and objects. Through careful design, various technical measures such as construction and protection are adopted to strictly control the release process of explosive energy and the crushing process of the medium, which must meet the expected requirements. The blasting and crushing effect must also control the blasting range, direction and the damage of blasting seismic waves, air shock waves, noise and broken and non-scattering within the prescribed limits.

According to the maximum allowable vibration speed of the blasting safety regulations, the maximum allowable explosive quantity at the time of a single explosion can be obtained by the following formulation $[2,12,13]$ :

$Q=R^{3}(v / K)^{\frac{3}{\alpha}}$ 
where: $R$ is the distance from the source of the explosion source to the object to be protected, $\mathrm{m}$; $v$ is the allowable vibration velocity of the location point of the building, $\mathrm{cm} / \mathrm{s} ; K$ is the medium correlation coefficient; soft rock takes 120-180; medium hard rock takes 80-120; hard rock takes $30-80 ; \alpha$ is the attenuation index, which is generally 1.5 to 1.75 .

Due to the fact that the foundation pit to be excavated and the adjacent structure of the adjacent exhibition center are only $4.6 \mathrm{~m}$, the vibration and safety requirements of the buildings around the foundation pit cannot be met.

\subsection{Hydraulic splitting}

The hydraulic splitting machine captures the brittle nature of rock and concrete, and uses the wedge principle to design - hydraulic cracking of the rock, cracking and rock without vibration and sound $[14,15]$.

Process safety, environmental protection, flexibility of use, accuracy, but the cracking rod seal is easy to leak oil, frequent changes; only cracks can be generated after splitting, and the crusher is required to be used twice. Broken, construction efficiency is low. According to the actual production data statistics of a test section at the construction site, the amount of breakage during overtime work is less than $30 \mathrm{~m}^{3} /$ day.

\subsection{Carbon dioxide phase change fracturing technology}

As a new and efficient cracking and excavation technology, carbon dioxide $\left(\mathrm{CO}_{2}\right)$ cracking technology has been gradually promoted in the field of rock mass mining and coal mine excavation. The basic components consist of a liquid storage tube, an ignition heat generating agent, an energy dissipating sheet and an unloading head [7], as shown in Fig. 1. The detonator is activated, and the high-voltage current causes a chemical reaction of the activator material in the blast tube to generate a large amount of heat, which causes the phase change of the liquid carbon dioxide to be converted into rapidly expanding high-pressure gaseous carbon dioxide. The volumetric expansion of liquid $\mathrm{CO}_{2}$ is more than 600 times after thermal phase transformation, and the instantaneous bursting pressure ranges from 100 to $300 \mathrm{MPa}$, which can meet the requirements of cracking and displacement of coal rock and most rock mass [16-19]. The principle of this technology is that the high-pressure gas generated by the liquid $\mathrm{CO}_{2}$ phase transition is instantaneously released, and the stress wave propagates to the surrounding. The stress wave and the high-energy gas cause new cracks in the rock/coal body on the one hand, and promote the expansion and development of the primary crack on the other hand. To achieve the effect of cracking. Due to the low tensile strength of the coal body, the coal block is divided into appropriate block degrees by rationally arranging the carbon dioxide-induced splitting pipe, and thrown into the mining space to achieve the purpose of increasing the lump coal rate.

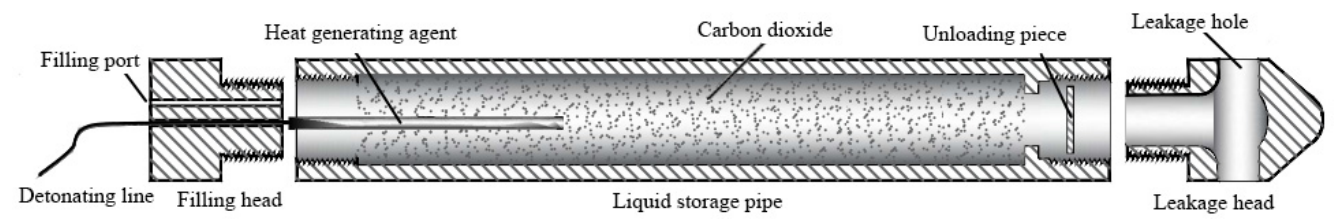

Fig. 1. $\mathrm{CO}_{2}$ fracturing structure

(1) Liquid storage pipe: storage of liquid $\mathrm{CO}_{2}$;

(2) Filling head: filling liquid $\mathrm{CO}_{2}$, closing the inner cavity of the liquid storage tube;

(3) Ignition heating component: after energization excitation, providing heat for liquid $\mathrm{CO}_{2}$ gasification;

(4) Unloading piece (constant pressure damaged piece): sealing the inner cavity of the liquid storage pipe to control the amount of energy released by the $\mathrm{CO}_{2}$ cracker; 
(5) Leakage head: Provides a high pressure gas release passage.

The $\mathrm{CO}_{2}$ phase change fracturing process is the instantaneous release of high-pressure gas generated by liquid $\mathrm{CO}_{2}$ phase transformation, which causes the rock to break and loose, and will generate certain vibration. The cracking tubes used in the field are different, and their vibration effects are different. At present, there is no relevant theoretical calculation formula for the vibration effect of carbon dioxide cracking process and dynamic damage of rock mass, but many scholars have conducted field tests on the vibration effect of carbon dioxide cracking process and analyzed its attenuation law.

\section{On site test and results analysis}

\subsection{Fracture parameter design}

According to the width of the excavation foundation pit and the distance from the building, three carbon dioxide phase change cracking parameters were designed, as shown in Table 1. At the same time, the TC-4850 blasting vibration self-recording instrument was used to monitor the vibration velocity and acceleration value of the rock mass during the cracking process. Combined with the characteristics of this project, the measuring line is arranged on the mid-perpendicular line of the broken hole connection line, and each measuring point is provided with three directions of vertical direction, horizontal radial and horizontal tangential direction.

Table 1. Fracture parameter design

\begin{tabular}{|c|c|c|c|c|c|}
\hline No. & Cracking tube model & Resistance line $/ \mathrm{m}$ & Deep $/ \mathrm{m}$ & Spacing $/ \mathrm{m}$ & Number of split tubes \\
\hline 1 & 100 & 2 & 3 & 2.5 & 5 \\
\hline 2 & 100 & 2 & 3 & 2 & 5 \\
\hline 3 & 85 & 1.5 & 3 & 2 & 5 \\
\hline
\end{tabular}

\subsection{Results analysis}

Fig. 2 shows the final cracking effect obtained by using carbon dioxide phase change cracking technology in the field. According to the on-site cracking situation, the carbon dioxide phase change cracking technique mainly forms a wide crack and causes the rock to loosen. There are fewer new cracks in the fracture, mainly primary cracks. Rocks that are judged to be loose will expand and break in natural cracks, and the formed stones are larger.
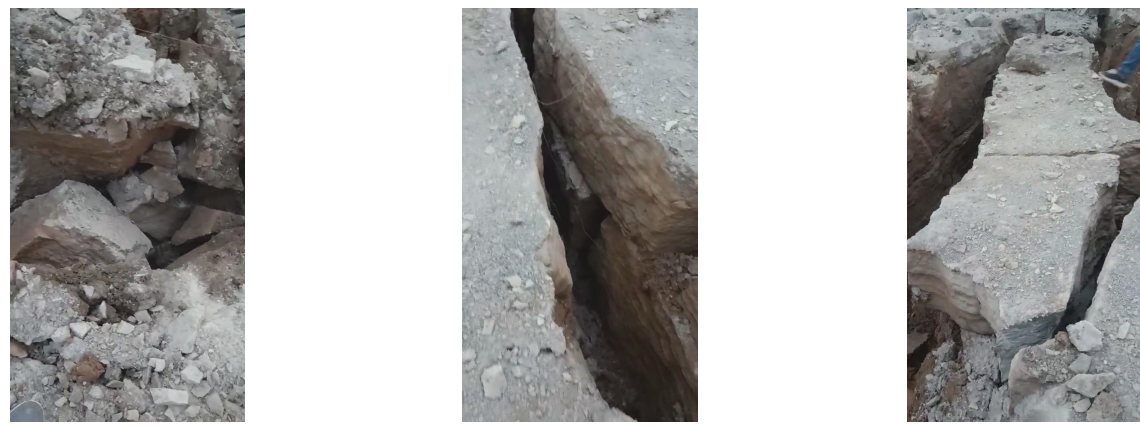

Fig. 2. On-site cracking effect

Fig. 3 shows the vibration attenuation law of carbon dioxide cracking process under three different cracking parameters. It can be found that the vibration decay of $\mathrm{CO}_{2}$ phase change cracking process is fast and the influence range is small. Among the third cracking parameters, 5 meters from the source can already meet the safety requirements. The vibration response safety range obtained by using the carbon dioxide phase change cracking technology in the foundation pit excavation of Li Qiyue, Liu Xiaoxiong and Xie Xiaofeng [19-22] is the same, that is, when the 
distance between the monitoring points and the gun source is 5 meters, the vibration velocity is less than $2.5 \mathrm{~cm} / \mathrm{m}$.
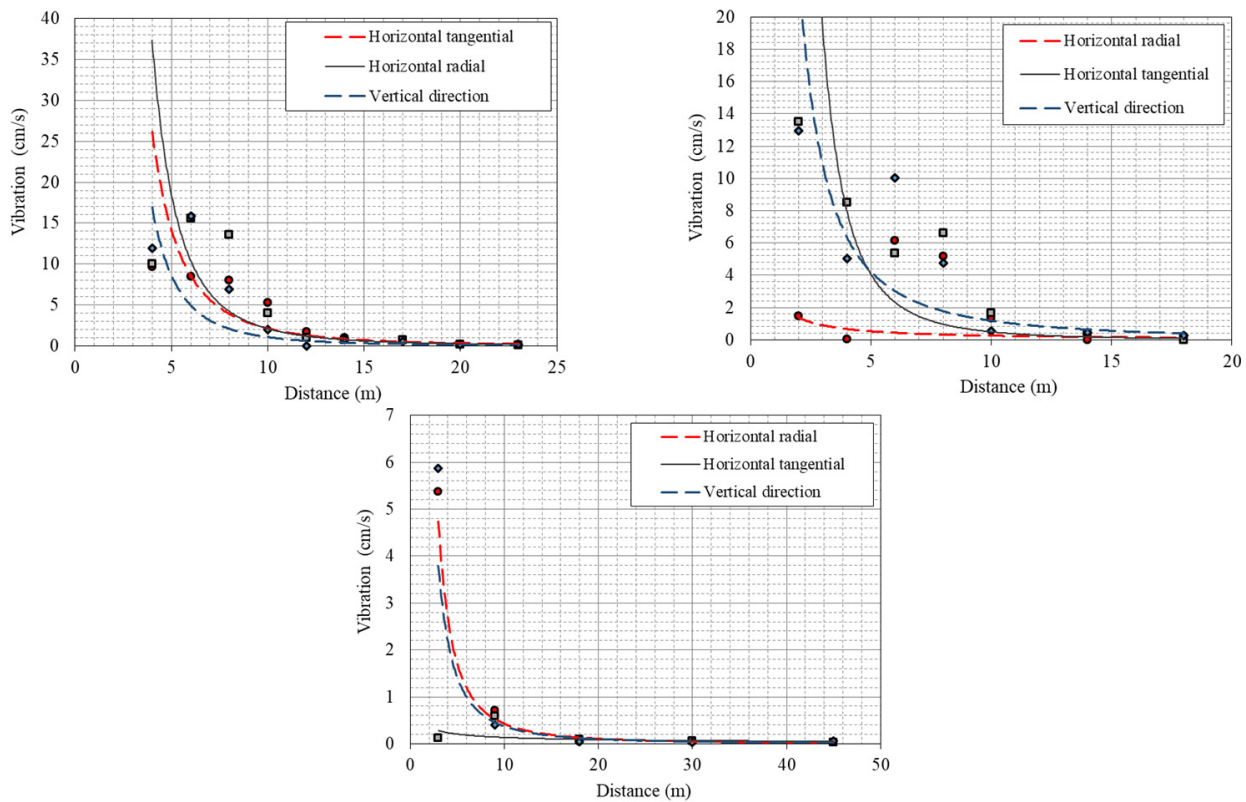

Fig. 3. Vibration attenuation law of carbon dioxide cracking process under three different cracking parameters

\section{Environmental impact and economic comparison analysis}

In order to better analyze the applicability of three rock breaking methods in open pit excavation, the effects, complexity, danger, environmental protection and contract unit price of three rock breaking methods are compared and analyzed, as shown in Table 2.

Table 2. Three methods are compared and analyzed

\begin{tabular}{|c|c|c|}
\hline Project name & Safety and environmental & $\begin{array}{c}\text { Contract } \\
\text { price } / \mathrm{m}^{3}\end{array}$ \\
\hline $\begin{array}{c}\text { Controlled } \\
\text { blasting }\end{array}$ & $\begin{array}{c}\text { The risk is high, and various safety accidents are easily occurred } \\
\text { within the scope of safety warning, such as cracking surrounding } \\
\text { buildings, equipment, and wounding people. Produce noise, harmful } \\
\text { gases, blasting flying stones, etc. }\end{array}$ & 130 Yuan \\
\hline $\begin{array}{c}\text { Hydraulic } \\
\text { splitting }\end{array}$ & $\begin{array}{c}\text { Safe and easy to manage. Hydraulic splitting is a non-explosive } \\
\text { dangerous goods. No special types of work such as blasting are } \\
\text { required during operation. The crushing agent can be purchased, } \\
\text { transported and used like other ordinary goods. Environmentally } \\
\text { friendly materials, silent, vibration-free, fly-free, non-toxic, dust-free. }\end{array}$ & 230 Yuan \\
\hline $\begin{array}{c}\text { Carbon dioxide } \\
\text { phase change } \\
\text { fracturing } \\
\text { technology }\end{array}$ & $\begin{array}{c}\text { Safe and easy to manage. The cracking process uses a carbon } \\
\text { dioxide-induced splitting tube to reduce on-site construction } \\
\text { procedures and high efficiency. No sound, no vibration, no flying } \\
\text { stone, no toxic gas, no dust. }\end{array}$ & Less than \\
250 Yuan \\
\hline
\end{tabular}

\section{Conclusions}

Although the blasting method has high efficiency and low price, the vibration generated is large, which has a great influence on the surrounding environment and high risk. The hydraulic splitting effect is very slow, which not only affects the construction time, but also increases the 
management cost. The carbon dioxide phase change fracturing technology has high price, but it can effectively ensure the construction safety and the influence on the surrounding. So the carbon dioxide phase change fracturing technology is a relatively reasonable construction method.

According to the on site test, in order to ensure the safety of the site construction safety cracking tube model is 85 , that is to say diameter of split tubes is $85 \mathrm{~mm}$. The effect of carbon dioxide phase change cracking is related to the formation of the air surface, so a good air surface should be made during the construction process in order to improve the cracking effect.

\section{References}

[1] Ding S., et al. Study on the effect of damping hole on reducing blasting vibration under the excavation of subway foundation pits. Journal of Railway Science and Engineering, Vol. 4, 2014, p. 16.

[2] Jiang N., Chuan-Bo Z., Gang L. Blasting vibration safety criterion of railway tunnel concrete lining. Journal of Central South University (Science and Technology), Vol. 43, Issue 7, 2012, p. 2746-2750.

[3] Xiong D., et al. Analysis of the blasting vibration characteristics during light rail tunnelling. Journal of Railway Science and Engineering, 2015.

[4] Global J. Cardox system brings benefits in the mining of large coal. Coal International, Vol. 243, 1995, p. 27-28.

[5] Xia Jun, Li Bihong, Chen Dingding $\mathrm{CO}_{2}$ liquid-gas phase expansion rock breaking technology. Mining Technology, Vol. 6, 2016, p. 119-121.

[6] Xia Jun, et al. Carbon dioxide liquid-gas phase variable expansion rock breaking technology and application. Engineering Blasting, Vol. 3, 2018, p. 10.

[7] Singh S. Non-explosive applications of the PCF concept for underground excavation. Tunnelling and Underground Space Technology, Vol. 13, Issue 3, 1998, p. 305-311.

[8] Wei Gang, et al. Experimental study on coal falling in liquid $\mathrm{CO}_{2}$ blaster. Coal Mining, Vol. 14, Issue 1, 2009, p. 22-24.

[9] Zhu Yucheng, Zhou Haifeng, Li Haodang Carbon dioxide gun treatment of fully mechanized mining faceway triangle suspension. Coal Mine Safety, Vol. 44, Issue 8, 2013, p. 144-146.

[10] Wei Haidong Application of carbon dioxide pre-crack blasting forced topping technology in 80124 fully mechanized mining face. Shandong Coal Science and Technology, Vol. 8, 2017, p. 70-71.

[11] Zeng Yongqing Study on Blasting Vibration Effect for Carbon Dioxide Blasting. Institute of Rock and Soil Mechanics, Chinese Academy of Sciences, Wuhan, 2010.

[12] Bhandari S. Engineering Rock Blasting Operations. A.A. Balkema, 1997.

[13] Persson P.-A., Holmberg R., Lee J. Rock Blasting and Explosives Engineering. CRC Press, 2018.

[14] Lei Jin Application of anti-slide pile construction technology of hydraulic splitting machine. Jiangxi Building Materials, Vol. 4, 2015, p. 101-101.

[15] Qi Shiliang Application of hydraulic splitting machine in tunnel boulder treatment. Jilin Water Conservancy, Vol. 2, 2010, p. 27-30.

[16] Wang Haidong Outburst coal seam heading face $\mathrm{CO}_{2}$ controllable phase change cracking prevention technology. Coal Science and Technology, Vol. 44, Issue 3, 2016, p. 1-1.

[17] Fan Yingchun Application of carbon dioxide blasting and anti-reflection technology in low permeability coal seams. Zhongzhou Coal, Vol. 5, 2015, p. 1-3.

[18] Fan Yingchun, Huo Zhonggang, Yao Yonghui Deep-hole pre-split blasting anti-reflection technology under complex conditions. Coal Mine Safety, Vol. 45, Issue 11, 2014, p. 74-77.

[19] Zhou Xihua, et al. Industrial test of underground liquid $\mathrm{CO}_{2}$ blasting anti-penetration. China Safety Production Science and Technology, Vol. 11, Issue 9, 2015, p. 76-82.

[20] Li Qiyue, et al. Application of liquid $\mathrm{CO}_{2}$ phase change rock breaking technology in subway foundation pit excavation. Journal of Railway Science and Engineering, Vol. 15, Issue 1, 2018, p. $163-169$.

[21] Xie Xiaofeng, et al. Review of liquid $\mathrm{CO}_{2}$ phase transformation rock breaking technology. Journal of Railway Science and Engineering, Vol. 15, Issue 6, 2018.

[22] Liu Xiaoxiong, et al. Study on vibrational energy distribution of rock-solid phase change in liquid carbon dioxide. Mining and metallurgy engineering, Vol. 38, Issues 181(3), 2018, p. 5-10. 